\title{
CHALLENGES IN THE DEVELOPMENT OF BULGARIAN HIGHER EDUCATION SYSTEM DURING POST-CRISIS PERIOD
}

\author{
Venelin Terziev', ${ }^{1}$ Olga Andreeva ${ }^{2}$, Marin Georgiev ${ }^{3}$, Vladimir Klimuk ${ }^{4}$ \\ ${ }^{1}$ Full Member of the Russian Academy of Natural History, Professor, Eng., D.Sc. (National \\ Security), D.Sc. (Economics), D.Sc. (Social Activities), Ph.D. Georgi Rakovski Military Academy, \\ Sofia, Bulgaria; University of Rousse, Rousse, Bulgaria; Kaneff University Hospital, Rousse, \\ Bulgaria, vkterziev@gmail.com \\ ${ }^{2}$ Associate Professor, Ph.D., Rostov State University of Economics, Rostov-on-Don, Russia, \\ olvandr@ya.ru \\ ${ }^{3}$ Ph.D., Kaneff University Hospital, Rousse, Bulgaria, clementon@abv.bg \\ ${ }^{4}$ Associate Professor, Ph.D., Baranavichy State University, Republic of Belarus, \\ klimuk-vv@yandex.ru
}

\begin{abstract}
This work represents an attempt to define a group of issues existing in the Bulgarian higher education system. Summarizing and specifying them is a matter of detailed analysis that would explain its low level and opportunities for a change. The authors of this paper have made an attempt for a brief comparative analysis of the public rankings of European universities.
\end{abstract}

Keywords: development, European universities, education, Bulgarian universities.

\section{INTRODUCTION}

In times when Bulgarians are losing their spirituality and are lacking the values that have helped them survive and keep on going, we are trying to fit into the European and world educational and cultural space. Some of us insist that we deserve it by right, while others tend to think that we are already part of it and can now rest on our laurels...

Unfortunately, our not-so-realistic expectations cannot be fulfilled and do not coincide with attitude and behaviour of the communities surrounding us. It is always a right solution to look for the best in ourselves and present it in the best way, but above all we need to have a clear and precise idea of where we are, what we expect to happen to us and most importantly - how it can happen to us. This approach is especially vital nowadays, while overcoming the consequences of the pandemic outbreak, as we need to wake up and realize that we are not the centre of the universe. We need to look for possible ways to realize our ideas that will motivate our social development.

It is undoubted truth that the people, who rely on their educational and cultural traditions, upholding and 
developing them, get that special place in the public development as they should not show off, interpret or brag about, because they themselves are such and this is their life style. And yet more difficult to understand it becomes for us from historical point of view, because this truth should be written with our Bulgarian alphabet and it has been made by us.

\section{CHALLENGES IN THE DEVELOPMENT OF BULGARIAN HIGHER EDUCATION SYSTEM DURING POST- CRISIS PERIOD}

Recently a lot has been said and written about the development of Bulgarian higher education. Very often we strive to find ourselves among top European and world countries and we are glad when accidentally or not we appear on a certain rank list for the first time. The fact that we are on some list of "candidates" is an important achievement itself. Unfortunately, the process of restructuring this particularly significant element of our education system is incomplete. Moreover, during transformation we have proved too unprepared for such dynamic political changes. The market mechanisms have confused the process of restructuring our education system, have blocked it so that it almost is not affected by the external factors.

Our people are pretty skilful at writing strategies and action plans that seem brilliant and interesting enough according to the European standards, but our existence in this so-called educational space or, in other words, our place in the society, is getting more and more insignificant, i.e. where very few narrow and not so important claims can be met. Of course there are some beautiful and impressive exceptions that make us happy, however, this mechanism has long been autonomously dead and activates only when it has to defend its survival or to note that it is on the map. The academic autonomy of higher education institutions has led to quite critical deviations from the normal functioning of the educational process. Some of the them include: lack of respect towards the supervisor's authority, election of the collective management bodies in a not very democratic way, increase of professional areas in which educational process takes place, without having a proven capacity, lack of any planning of these processes and a number of others.

These ongoing processes are hardly unnoticed by the numerous analysts and researchers, by those who have to and are charged with creating strategic documents. However, the change, or more precisely the process of changing, turns out to be so difficult or almost impossible to achieve that none has happened in more than thirty years.

The market mechanisms that created certain conditions for the establishment of a large number and variety of institutions for training and science development, also created disproportions that will be difficult to overcome and that after all created the situation in which we are searching ourselves in the list, and moreover - in the end of the list, and not to be where we maybe expect to be!?

There are 50 higher education institutions in Bulgaria and for the last years the admission quota of new students cannot be reached. Some of the reasons for this matter are due to the ongoing demographic processes and growing problem of population decline in the country, but this is far not the main problem in the functioning of our educational system (Terziev, 2019; Terziev, 2019a).

A return to old educational methods and even successful policies from the past is almost impossible because they were established in compliance with the current realities to address current issues. The existing ones nowadays do not answer many questions, while the competitors around us combine both past and future and are in the top lists of these rankings.

Opponents of all forms of assessment would say that the criteria are not the best, the conditions are different and the funding is insufficient. But even if we assume that their standpoint is fair and true, we are in a certain situation and conditions where we shall make the right and most effective decisions.

In order to justify these statements, let's look at the results of one of the many rankings that were published this month. It identifies the most popular universities in Europe. In order to be included in the ranking of UniRank, the universities shall cover certain criteria defined by it, i.e. they need to be certified and/or accredited by the relevant higher education organization in each country, to offer at least four-year bachelor's programmes and masters or doctoral studies and to administer their studies mainly in a traditional form.

No Bulgarian university appeared in the Top 200 (Fig. 1) of this ranking, but it is more interesting how the education institutions are distributed in Europe and which countries are on the list. Leading positions are occupied by the British education system - almost $24 \%$ of the universities are ranked there, followed by Germany with nearly $16 \%$. After them are Spain and France. In practice, these four countries determine a group of elite universities. Other positions are held by representatives of the Netherlands - 10 universities, Italy - 9 universities, Switzerland and Russia - 7 universities each, etc. The Balkan countries are so far represented only by Greece. 


\section{Top 200 Universities in Europe 2020 (\%)}

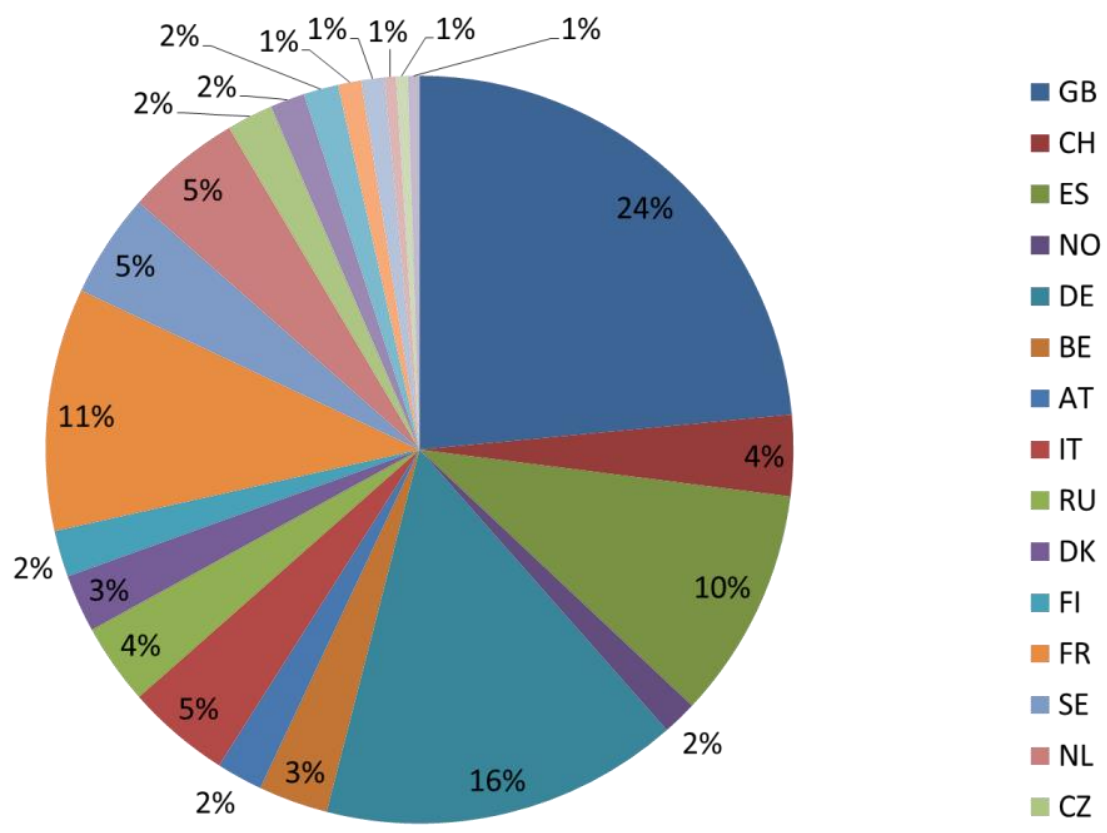

Fig. 1. Top 200200 Universities in Europe (2020).

There are dozens of other rankings and universities assessment systems available to public. In some best cases, several Bulgarian universities are ranked in higher positions. Among them are "St. Kliment Ohridski" University of Sofia, Technical and Medical University of Sofia.

Without having claims for a detailed analysis, the cracks in the Bulgarian system of higher education should be filled and a set of problems, which are now put on the table, should be solved in an objective and correct manner. We can generalize them in two groups. The problem of surplus and the problem of deficit.

Obviously, there is a sufficient and, perhaps, quite large number of educational institutions. They are distributed unevenly in the country in terms of scientific infrastructure. Most of the institutions are concentrated in the capital and several in the country's largest cities. Most of them offer programmes of study in almost all professional fields with few exceptions. Therefore, lack of qualified staff is not the issue, yet quite the opposite, we should have enough experts in almost all areas. Regardless of the state standards and requirements for the accreditation procedures, not all institutions (even paid ones) provide quality service. This process involves at least two parties - those who offer it and those who receive it. It won't be difficult to find a set of viewpoints criticising both, but justifiably, the result does not meet our European standards and in particular our expectations for many members of these two groups. In practice and in theory there is a problem in the effectiveness of this process, which of course is continuous and quite complex in nature, making it difficult to manage. Here is just one example that hardly answers all the questions that arise. In the last few years people have had more restrictive attitude towards a number of study programmes in the field of economics and administration and management, which shows us that in recent years there have been a sufficient amount of graduates in the field. At the same time, almost every social survey or questionnaire on this matter reports a shortage of well-trained managers, and even specialists in the field of finance and accounting. The answers and criticisms can be formulated in many ways, such as that almost all universities offer a programme of study in these areas and the three Bulgarian universities of economics are in a particularly competitive environment; that studying in some of them is dictated by direct economic benefit to accept a certain number of students; that one of the universities is located in the area with a relatively small population and not very good road infrastructure and communication relations, which makes it isolated or in worse positions than the others. In essence, all these statements are true, but they do not provide an answer to the question - why with such an excess of opportunities there is still a shortage of professionals in the real primary market?

In other cases, some of the engineering studies remain promising and necessary, yet still not very popular among students, even though the admission level of such programmes is relatively low.

Until we solve the problems in both these directions and clarify their reasons, there is no way to implement 
and even think about a successful strategy in the field of higher education. It cannot be solved by itself and there is no way to adapt to the situation, because the main element in the management process is planning. Planning effective actions in this direction is a reflection of highest level in management and cannot be an action of a single individual, or even of an entire ministry. Therefore, before moving from one period of financing of education (according to the established practice of the European Union) to another we must strive to solve these crisis issues, which are not a consequence of a pandemic situation or other crisis phenomena, but of the lack of professional analysis, proper planning and effective policy (Terziev, 2020a; Terziev, Lyubcheva, Solovev, 2020b).

\section{CONCLUSION}

So when we are looking for solutions to economic, political or other problems that happen and will continue to happen to us every day, we must think in perspective about the educational and cultural processes. Only their successful solution will lead to the much-desired efficient political and economic transformations. They are about to happen to us again in the near and distant future, and they will be of great importance to us. But we must be prepared to feel more confidence to take the position we think we deserve. Otherwise, the pointlessness will overwhelm us and give us unnecessary self-confidence, rivalry and malice, but it will not help us overcome our self-sufficiency.

Let us make more efforts for spiritual development and growth and not for survival so that our movement forward does not go together with decline, but with the meaning of successful development!

\section{REFERENCE LIST}

Terziev, V. (2019). Managing changes in the system of higher education. // 23rd International Scientific Conference Knowledge in practice (13-15.12.2019), Bansko, Bulgaria, Institute of Knowledge Management, Skopje, 35, 2019, 1, pp. 347-349, ISSN 1857-923X (for e-version) ISSN 2545 - 4439 (for printed version).

Terziev, V. (2019a). The development of education in Bulgaria. // Proceedings of SOCIOINT 2019-6th International Conference on Education, Social Sciences and Humanities 24-26 June 2019 - Istanbul, Turkey, International Organization Center of Academic Research, Istanbul, Turkey, 2019, pp. 263-266, ISBN: 978-605-82433-6-1.

https://www.4icu.org/top-universities-europe/ (2020).

Terziev, V. (2020a). Factors influencing education system. // Economic and Social Development (Book of Proceedings), 50th International Scientific Conference on Economic and Social Development Development, 13-14 February 2020, Chelyabinsk, 2020, pp. 651-656, ISSN 1849-7535.

Terziev, V., Lyubcheva, M., Solovev, D. (2020b). The interaction: business- education- investment for development. // Proceedings of INTCESS 2020- 7th International Conference on Education and Social Sciences 20-22 January, 2020 - DUBAI (UAE), International Organization Center of Academic Research, Istanbul, Turkey, 2020, pp. 865-869, ISBN: 978-605-82433-8-5. 